\title{
Qualitative Assessment and Reporting Quality of Intracranial Vessel Wall MR Imaging Studies: A Systematic Review
}

\author{
(D).W. Song, (DS.C. Guiry, (DH. Shou, (D)S. Wang, (D)W.R. Witschey, DS.R. Messé, (DS.E. Kasner, and (DL.A. Loevner
}

\begin{abstract}
BACKGROUND: Over the last quarter-century, the number of publications using vessel wall MR imaging has increased. Although many narrative reviews offer insight into technique and diagnostic applications, a systematic review of publication trends and reporting quality has not been conducted to identify unmet needs and future directions.
\end{abstract}

PURPOSE: We aimed to identify which intracranial vasculopathies need more data and to highlight areas of strengths and weaknesses in reporting.

DATA SOURCES: PubMed, EMBASE, and MEDLINE databases were searched up to September 2018 in accordance with the Preferred Reporting Items for Systematic Reviews and Meta-Analyses guidelines.

DATA ANALYSIS: Two independent reviewers screened and extracted data from 128 articles. The Strengthening the Reporting of Observational Studies in Epidemiology guidelines were used to assess the reporting quality of analytic observational studies.

DATA SYNTHESIS: There has been an exponentially increasing trend in the number of vessel wall MR imaging publications during the past 24 years $(P<.0001)$. Intracranial atherosclerosis is the most commonly studied intracranial vasculopathy $(49 \%)$, followed by dissections (13\%), aneurysms (8\%), and vasculitis $(5 \%)$. Analytic observational study designs composed $48 \%$ of the studies. Transcontinental collaborations showed nonsignificantly higher reporting quality compared with work originating from single continents $(P=.20)$.

LIMITATIONS: A limitation is the heterogeneity in study designs.

CONCLUSIONS: Investigations on the diagnostic utility of vessel wall MR imaging in less commonly studied intracranial vasculopathies such as dissections, aneurysms, and vasculitis are warranted. More consistent adherence to the Strengthening the Reporting of Observational Studies in Epidemiology guidelines should improve transparency and maximize effective synthesis for clinical translation. Diverse collaborative teams are encouraged to advance the understanding of intracranial vasculopathies using vessel wall MR imaging.

ABBREVIATIONS: CRS = complete reporting score; ICAD = intracranial atherosclerotic disease; STROBE = Strengthening the Reporting of Observational Studies in Epidemiology; $\mathrm{VWI}=$ vessel wall MR imaging

$\mathrm{V}$

essel wall MR imaging (VWI) is being increasingly used worldwide to evaluate intracranial vasculopathies. ${ }^{1}$ This increased utilization has paralleled a rise in the number of publications using VWI. Many narrative reviews report the application and utility of VWI for different types of vasculopathies. ${ }^{2,3}$ However, no study has systematically assessed the frequency or

Received July 15, 2019; accepted after revision September 24

From the Departments of Radiology (J.W.S., S.C.G., S.W., W.R.W., L.A.L.), Neurology (S.R.M., S.E.K.), Otolaryngology (L.A.L.), and Neurosurgery (L.A.L.), Hospital of the University of Pennsylvania, Philadelphia, Pennsylvania; and Department of Biostatistics, Epidemiology and Informatics (H.S.), University of Pennsylvania, Philadelphia, Pennsylvania.

This work was supported by the Radiological Society of North America Research and Education Foundation, through grant No. RSCH1929; the Institute for Translational Medicine and Therapeutics/Thomas B. McCabe and Jeannette E. Laws McCabe Fund for Junior Faculty (J.W.S.); and National Institutes of Health National Heart, Lung, and Blood Institute, R01 HL137984 (W.R.W.).

trends of VWI publications for all intracranial vasculopathies or the reporting quality.

Interpretation of data and secondary analyses from observational studies is often limited by the methodology and completeness of reporting. Reporting quality is important to critically

\footnotetext{
The content is solely the responsibility of the authors and does not necessarily represent the official views of the Radiological Society of North America Research and Education Foundation.

Please address correspondence to Jae W. Song, MD, MS, Department of Radiology, Division of Neuroradiology, Hospital of the University of Pennsylvania, 3400 Spruce St, Philadelphia, PA 19104; e-mail: jae.song@pennmedicine.upenn.edu; @jsongmd

- Indicates open access to non-subscribers at www.ajnr.org

$\equiv$ Indicates article with supplemental on-line tables.

http://dx.doi.org/10.3174/ajnr.A6317
}

AJNR Am J Neuroradiol 40:2025-32 Dec 2019 www.ajnr.org 
assess the strengths of studies, weaknesses, and generalizability as well as for investigators who want to assess the reproducibility of a study. The clinical and scientific utility of research data may be lost in poorly reported studies. The Strengthening the Reporting of Observational Studies in Epidemiology (STROBE) guidelines were developed to improve the quality of reporting of observational studies in medical research. ${ }^{4,5}$ We set out to systematically survey VWI publications by examining the types of vasculopathies studied as well as assessing the quality of reporting of analytic observational studies using the STROBE checklist. The aims of this study were to identify which intracranial vasculopathies may need more data and to highlight areas of reporting that could be improved.

\section{MATERIALS AND METHODS}

\section{Search Strategy}

The systematic review was conducted in accordance with the Preferred Reporting Items for Systematic Reviews and MetaAnalyses guidelines. PubMed, EMBASE, and MEDLINE were searched on September 12, 2018. To identify eligible studies, we searched keywords using the Boolean operators "OR" and "AND." Keywords covered imaging, vessel wall imaging, intracranial circulation, vasculopathy, and vascular disease terms (Online Table 1). A manual review of the citations of each included article was also performed. All foreign language articles were translated.

\section{Study Selection}

Two researchers independently reviewed all publications for inclusion. Inclusion criteria were the following: 1) case series or observational studies, 2) imaging humans, 3) intracranial arteries, 4) intracranial vasculopathies, 5) imaging of the arterial wall, and 6) MR imaging. Single case reports, conference abstracts, animal studies, and studies of the pediatric population were excluded.

\section{Data Extraction}

Two reviewers independently screened and extracted data from each study that fulfilled the inclusion and exclusion criteria. Disagreements were resolved by consensus. We collected the following data: publication characteristics (year of publication, countries of publication, funding sources), type of vasculopathy studied, study design (case series or analytic observational study), and subject enrollment design (prospective or retrospective). Analytic observational studies were identified using a published study design classification algorithm ${ }^{6}$ and included studies with comparator groups or that were designed as prevalence/cross-sectional or diagnostic accuracy studies. ${ }^{7-9}$ Studies that reported obtaining informed consent or explicitly reported prospective enrollment by the authors were categorized as prospective. Transcontinental collaborative publications were identified by author affiliations. Reporting quality was assessed using the STROBE checklist. ${ }^{4}$ Each STROBE item was assessed as $1=$ reported, $0.5=$ partly reported, or $0=$ not reported. A complete reporting score (CRS) per publication was calculated by summing the total number of items divided by 22 (the total number of STROBE criteria). Scores by article section (introduction, methods, results, and conclusions) were also calculated.

\section{Statistical and Sensitivity Analysis}

Categorical variables are expressed in counts and percentages. Distributions of continuous variables are summarized with means and SDs or medians and interquartile ranges. Agreement was calculated with an unweighted Cohen $\kappa$. Based on the goodness of fit, exponential and linear regression analyses were fit to test trends across time in the total number of VWI studies and analytic observational studies by year, respectively. The ShapiroWilks test was used to test normal distributions of CRS measures. CRS measures were calculated by a summary statistic (mean or median) based on the test for a normal distribution. The KruskalWallis test assessed differences among CRS scores by continent. Two sensitivity analyses assessed the robustness of the results. The first sensitivity analysis considered fulfillment of STROBE items reported in footnotes, bylines, and different sections of the article. A second analysis was conducted by considering fulfillment of STROBE items that were "partly reported" in any part of the article, including footnotes and bylines. Publication bias was assessed using the likelihood ratio $\chi^{2}$ test to compare the distributions of the intracranial vasculopathies of the included studies versus the excluded conference abstracts. SPSS Version 19 (IBM, Armonk, New York) was used for statistical analysis.

\section{RESULTS}

\section{Search}

The search strategy identified 2431 publications, among which 1635 were screened by title/abstract $(\kappa=0.77 ; 95 \%$ CI, $0.71-0.83$; $P<.01)$. Of those, 234 articles were selected for full-text review $(\kappa=0.89 ; 95 \%$ CI $0.82-0.96 ; P<.01)$. Manual review of the citations of the included articles yielded 807 citations, which were further screened by title/abstract $(\kappa=0.73$; $95 \%$ CI, $0.52-0.93$; $P<.01)$. Full data extraction for qualitative synthesis was performed on 128 articles identified from the initial and manual citation review (Fig 1; references in the On-line Appendix).

\section{Publication Trends}

The first article evaluating intracranial vessel wall characteristics from this systematic review was reported in 1994 evaluating intramural hematomas in dissections. ${ }^{10}$ The second publication was in 1995 and evaluated vessel walls for cerebral atherosclerosis. ${ }^{11}$ An exponentially increasing trend in the number of VWI publications during the past 24 years was seen (Fig 2) $(\beta=0.14$; $95 \%$ CI, $0.11-0.17 ; P<.0001)$. Asia published the highest number of publications (61\%) during the 24 years, followed by North America $(n=19)$ and Europe $(n=18)$. In 2014, transcontinental collaborative publications emerged, composing $10 \%$ of the included publications. Asia was part of $92 \%$ of the transcontinental collaborations (Fig $3 A$ ), and $46 \%$ of the transcontinental collaborations were between Asia and North America.

Most investigations were solely federally funded (39\%). Publications with mixed types of funding sources accounted for $21 \%$, with the most common combination being federal and medical society sources (54\%). No funding source was reported for $30 \%$ of all publications (Fig 3B).

Survey of studies focused on 1 vasculopathy revealed intracranial atherosclerotic disease (ICAD) to be the most commonly studied vasculopathy $(49 \%, n=62$, references in the On-line 


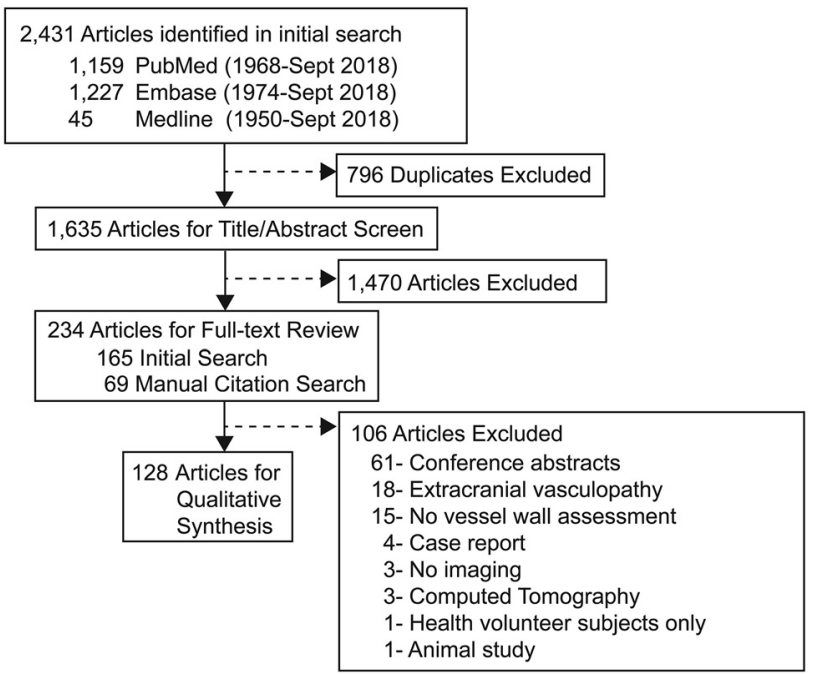

FIG 1. Systematic review of the data bases. From the initial data base search, 165 articles were identified for full-text review. Manual review of the citations of those 165 articles identified 807 citations that were further screened by title and abstract. This resulted in 69 articles for full-text review from the manual citation search. A total of 234 articles underwent full-text review, from which 128 articles met the predetermined inclusion and exclusion criteria.

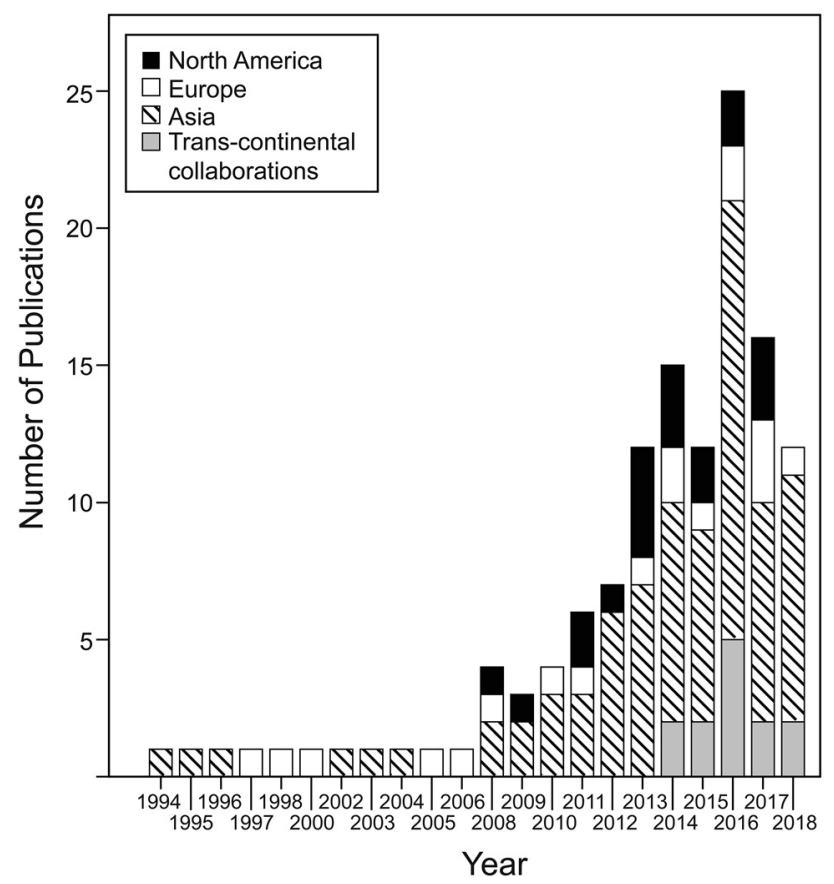

FIG 2. Annual number of publications using vessel wall MR imaging.

Appendix), followed by arterial dissection $(13 \%, n=16),{ }^{10,12-26}$ aneurysm $(8 \%, n=10),{ }^{27-36}$ vasculitis $(5 \%, n=6),{ }^{37-42}$ Moyamoya disease $(3 \%, n=4),{ }^{43-46}$ postendovascular changes $(2 \%, n=3),{ }^{47-49}$ and reversible cerebral vasoconstriction syndrome $(1 \%, n=1)^{50}$ (Fig $3 C$ ). Among the 16 publications investigating arterial dissections, 11 used $\mathrm{VWI}^{12,14-18,22-26}$ and the other 5 publications ${ }^{10,13,19-21}$ assessed intramural hematoma signal characteristics on conventional MR imaging. Note that $21 \%$ of the studies examined $\geq 2$ types of vasculopathies; a breakdown of the types of vasculopathies studied among these publications is further illustrated in the piein-pie chart.

Publication bias was assessed by comparing the number of intracranial vasculopathy types that were included in this study with excluded conference abstracts; the comparison showed no significant difference (On-line Table 2, $P=.95$ ).

\section{Study Designs}

Case series composed $52 \%$ of the publications, and $48 \%$ were analytic observational study designs. There was a significant yearly increase in analytic observational studies since 2000 ( $\beta=0.39$; 95\% CI, 0.26-0.51; $P<.0001)$. Most studies were conducted with prospective subject enrollment (50\%) compared with retrospective subject identification (44\%). Examples of prospective case series include studies that obtained written informed consent to study circle of Willis cadaveric specimens and characterize intracranial atherosclerotic plaque components, ${ }^{51}$ recruited 3 subjects to describe atherosclerosis enhancement characteristics by VWI, ${ }^{52}$ and methodologic articles reporting interrater/intrarater reliability ${ }^{53}$ and scan-rescan reproducibility. ${ }^{54}$

\section{STROBE Reporting Assessment}

The 62 analytic observational studies were evaluated for reporting quality using the STROBE checklist (Table) $(\kappa=0.76 ; 95 \% \mathrm{CI}$, $0.72-0.79 ; P<.001)$. The mean CRS for all studies was $0.64 \pm$ 0.10 . The introduction section had the highest and the methods had the lowest scores. Transcontinental collaborative publications showed higher scores $\left(\mathrm{CRS}_{\mathrm{all}}=0.67 \pm 0.05\right)$ compared with single-continent studies (Table) and multisite/single-continent collaborations $\left(\mathrm{CRS}_{\mathrm{all}}=0.63 \pm 0.12\right)$, though these results did not reach statistical significance $(P=.20)$.

Two sensitivity analyses were performed that showed the same direction of the results but notably did not reach statistical significance. First, a sensitivity analysis evaluating each study for items reported in any part of the article, including footnotes and bylines, showed higher scores from transcontinental collaborations compared with single-continent studies $(P=.30)$. A second sensitivity analysis considered all partially reported criteria as fulfilling reporting and also showed higher CRS measures by transcontinental collaborations than North American and European studies. The studies from Asia had only marginally higher CRS measures $(P=.27)$ (On-line Table 3).

On-line Table 4 reports the mean score per STROBE item for the 62 articles and checklist descriptions. Items 1 and 22 were scored separately because they reflect title/abstract and funding reporting, respectively. Most studies provided an informative abstract but did not indicate the study design in the title (item 1) to fully meet the STROBE criterion, resulting in a score of $0.52 \pm$ 0.13 . Also, $70 \%$ of the studies did not disclose whether there was a funding source (item 22), resulting in a score of $0.71 \pm 0.46$. The 2 introduction section criteria, evaluating the reporting of the scientific background and rationale (item 2) and specific objectives or hypothesis (item 3), scored the highest among all sections.

The methods section included 9 criteria. No publication reported a sample size determination (item 10). Explicitly presenting key elements of the study (item 4) also scored low 

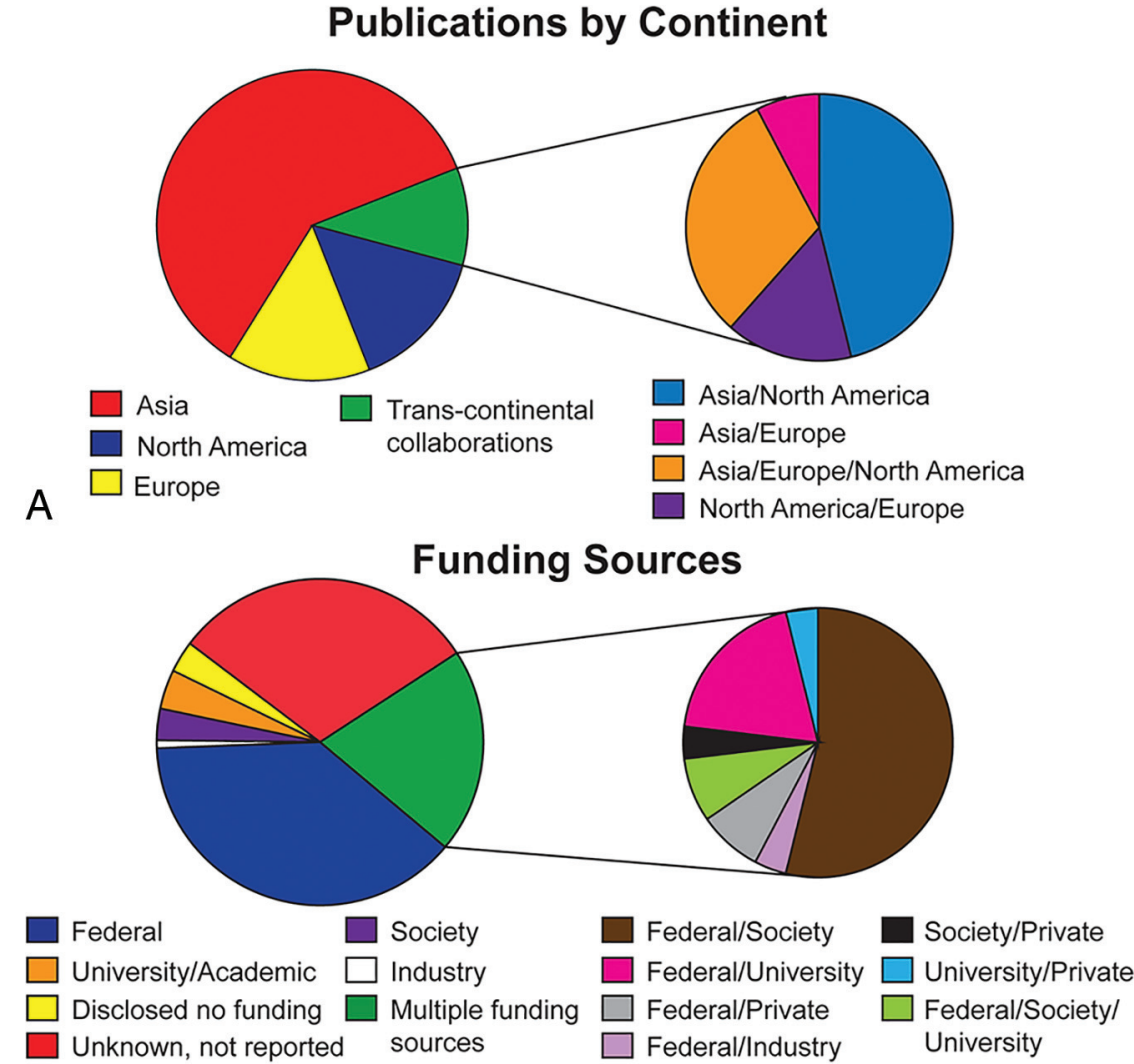

B

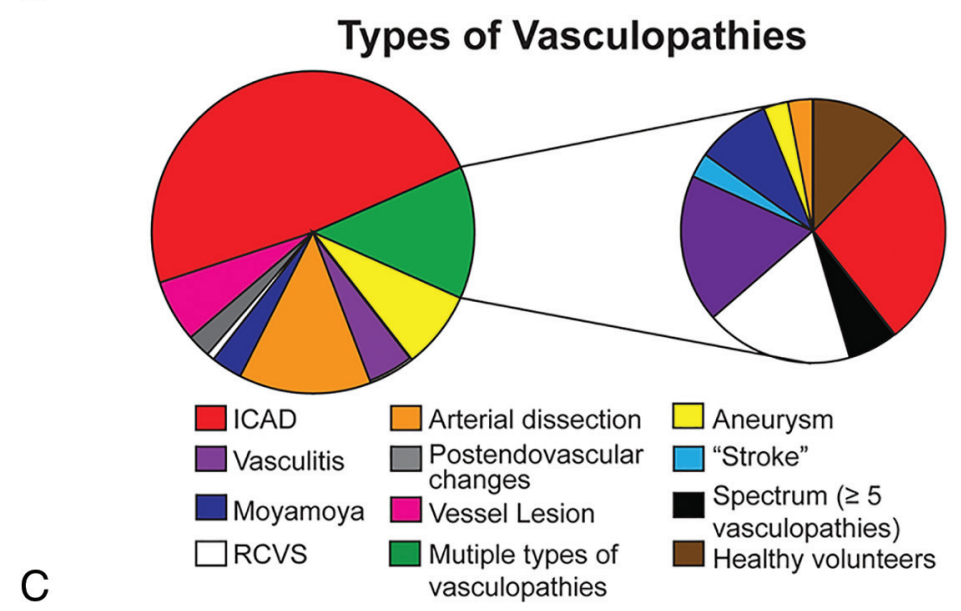

FIG 3. Distribution of publications by funding source, continent and intracranial vasculopathy. $A$, Distribution of publications by continent is shown. Distribution of transcontinental collaborations is further elaborated to show 4 different groups of collaborating partners. $B$, Distribution of different funding sources and the combination of funding sources are shown. C, Distribution of studied intracranial vasculopathies are shown. RCVS indicates reversible cerebral vasoconstriction syndrome.
$(0.08 \pm 0.24)$. Although $73 \%$ of the studies reported a prospective or retrospective subject enrollment method, few studies named the study design type. ${ }^{5}$ Clearly defining outcomes, exposures, predictors, confounders, and diagnostic criteria (item 7) also had a low score (0.34 \pm 0.32); for example, only $14 \%$ of the 43 publications studying ICAD reported diagnostic criteria for cardiovascular risk factors such as hypertension. The importance of reporting diagnostic criteria for hypertension is emphasized in light of the new 2017 American Heart Association classifications of hypertension and evolving definitions. ${ }^{55}$

Five criteria were included in the results section. Reporting of the study participants and information on exposures and potential confounders (item 14) was suboptimal $(0.45+0.19)$. Publications lacking information on confounders such as race/ethnicity were scored as partial reporting. Only 8 studies $^{18,56-62}$ reported race/ethnicity, among which 5 studies ${ }^{18,56-59}$ reported the information in the discussion section as a limitation of generalizability. Twenty-four publications originated from Asia, were single-center studies, and did not report a description of ethnicity; in these studies, one could assume that all enrolled subjects were Asian but clarity in reporting could be strengthened.

In the discussion section, generalizability (item 21) scored the lowest $(0.26 \pm 0.44)$. Most studies were single-center studies $(74.2 \%)$, but this was not commonly addressed as a limitation for external validity. A discussion on limitations and reporting direction/magnitude of potential bias (item 19) also scored

\section{STROBE complete reporting scores ${ }^{2}$}

\begin{tabular}{llccrc}
\hline & CRS $_{\text {All }}$ & CRS $_{\text {Introduction }}$ & CRS $_{\text {Methods }}$ & CRS $_{\text {Results }}$ & CRS $_{\text {Discussion }}$ \\
\hline All $(n=62)$ & $0.64(0.10)$ & $1.00(0)$ & $0.56(0.22)$ & $0.60(0.20)$ & $0.63(0.25)$ \\
North America $(n=11)$ & $0.62(0.10)$ & $1.00(0)$ & $0.52(0.11)$ & $0.56(0.22)$ & $0.69(0.28)$ \\
Asia $(n=40)$ & $0.65(0.11)$ & $1.00(0)$ & $0.61(0.17)$ & $0.65(0.20)$ & $0.63(0.25)$ \\
Europe $(n=6)$ & $0.58(0.14)$ & $1.00(0)$ & $0.42(0.15)$ & $0.60(0.15)$ & $0.63(0.19)$ \\
Trans-continental collaborations $(n=5)$ & $0.67(0.05)$ & $1.00(0)$ & $0.60(0.07)$ & $0.64(0.11)$ & $0.73(0.10)$ \\
\hline
\end{tabular}

\footnotetext{
${ }^{a}$ CRS measures reported in means (SDs) or medians (interquartile range). Summary statistics were chosen on the basis of the test for normality.
} 
poorly $(0.55 \pm 0.24)$, with most studies partially fulfilling this item due to an absence of a discussion on the direction and magnitude of the bias.

\section{DISCUSSION}

The increasing trend in the number of VWI publications and more transcontinental collaborations during the past 24 years suggest the widespread interest in the diagnostic utility of VWI. Evaluation of the reporting quality of analytic observational studies using the STROBE checklist highlighted strengths and weaknesses in the current literature. Subgroup analyses showed that transcontinental collaborations yielded higher CRS measures compared with single-center/single-continent and multicenter/ single-continent publications, suggesting an advantage for multicultural, diverse collaborative teams. Notably, the results did not reach significance, potentially due to the relatively small number of transcontinental publications.

A survey of the literature to date shows Asia as the leading contributor of VWI publications and ICAD to be the most commonly studied vasculopathy. Fewer VWI studies were identified evaluating arterial dissections, aneurysms, vasculitis, and Moyamoya disease. More effort is warranted to further understand the diagnostic utility of VWI in these less commonly studied intracranial vasculopathies.

Given that stroke is one of the leading causes of morbidity and mortality worldwide and a widespread public health problem, it is not surprising to see federal funding supporting many of the VWI investigations across all continents. Medical societies such as the Dutch Heart Foundation, American Society of Neuroradiology, Radiological Society of North America, and American Heart Association also emerged as common funding sources, showing societal missions to improve stroke outcomes. Nearly one-third of the studies did not disclose a funding source, reflecting either no funding source or funding that was not disclosed.

The availability of the STROBE guidelines has encouraged many research domains and medical specialties to improve reporting quality ${ }^{63,64}$ and ultimately improve research reproducibility. Assessment of reporting quality of VWI publications has not yet been evaluated. Our results show a CRS of 0.64 for the 62 analytic observational VWI studies. The results of this study highlight areas where reporting of analytic observational studies are good, along with other areas where improvements are needed. In particular, there is a need for studies to improve the clear reporting of definitions of exposures, predictors, and potential confounders (item 7). The lack of clearly defined diagnostic criteria becomes important when, for example, guidelines are updated; in 2017, the American Heart Association changed the blood pressure guidelines, with some secondary analyses suggesting that the new classification correlates with different prevalence rates and outcomes. ${ }^{65,66}$

Study size calculations (item 10) were not reported in any study. Sample size estimates are informative because they indicate the magnitude of the aimed effect and address whether there were challenges with recruitment due to drop-out or attrition bias. $^{5}$
Additional areas of weakness in reporting included the description of study design (item 4) and settings and locations (item 5). Reporting a prospective or retrospective enrollment design only is insufficient. For example, a cross sectional study could assess imaging findings on a subject at 1 time point using a prospective enrollment design or the subject could be identified retrospectively from a registry.

In the discussion, reporting the generalizability or external validity (item 21) of the results was also noted to be a weakness. Generalizability is evaluating the extent to which the results of the publication can be applied to other settings and populations and is important for the reader to see whether the results are applicable to his or her own practice setting.

Analysis of reporting quality by continent showed that transcontinental collaborations had higher CRS measures (Table). Collaborations are encouraged for the cross-pollination of ideas, to increase recruitment, or to enhance generalizability by coordinating a multisite study, among other advantages. ${ }^{67}$ Our findings suggest an additional advantage of higher reporting quality. Multilingual authors and increased diversity within teams from different continents may be possible explanations for this finding.

This systematic review has some limitations. First, neuroradiology research often reports innovative techniques and drives cutting-edge methods that are not tested as part of larger epidemiologic studies. These technologic-advancement publications are typically of smaller scale and are "proof of concept" studies that are designed differently but may have larger impact. The STROBE guidelines do not always fit this radiology research framework. However, as an assessment for completeness of reporting with consistency in evaluation by 2 independent raters, the results provide at least a basis of reporting quality among VWI publications. Second, classifying studies as case series or analytic observational studies was often challenging due to the heterogeneity in study designs. Many of the included studies did not fit traditional epidemiologic study designs. This challenge has been addressed in other systematic review methodologies, and an algorithm has been tested to appropriately classify study designs for systematic reviews. We based our classification as descriptive (case series) or analytic observational studies following a simplified version of this algorithm. ${ }^{6}$ Third, methodologic quality was not assessed because the aim was to identify trends in VWI publications rather than conduct a quantitative meta-analysis. Instead, an assessment of reporting quality was conducted to highlight areas for improvement.

Fourth, use of the STROBE checklist is inconsistently recommended in author guidelines among journals, which could be a confounder in our analysis. Notably, some journals have their own checklists requiring a statement on data-sharing and opensource availability, which also improve transparency of the conducted research. As a future direction, an assessment of the journals can be conducted to assess CRS measures by journal Impact Factor as well as explicit author instructions to follow the STROBE checklist. Finally, the CRS was calculated using the STROBE guidelines, and items were scored by section as determined by the STROBE checklist. Studies that did not report items 
in the correct section per the STROBE guidelines were not considered as fulfilling the criteria. This method may underestimate CRS measures. To account for this issue, we performed a sensitivity analysis with items scored as reported if present in any part of the article, including footnotes and author bylines. This sensitivity analysis yielded similar conclusions. A second sensitivity analysis considering partially reported items as completely reported showed a similar direction of the results.

\section{CONCLUSIONS}

We systematically assess VWI publications to identify trends and assess reporting quality. Our results show that ICAD is the most common intracranial vasculopathy studied. The utility of VWI for ICAD, and for other types of intracranial vasculopathies will likely benefit from additional rigorous studies. We also highlight deficiencies in the reporting of analytic observational VWI studies. Transcontinental collaborative effort yielded a higher reporting quality, though this result did not reach statistical significance. Nonetheless, there may be advantages to diverse and multilingual cross-cultural teams. More consistent adherence to STROBE guidelines should improve transparency and maximize effective synthesis and clinical translation of findings for future studies.

Disclosures: Jae W. Song—RELATED: Grant: Radiological Society of North America, Comments: Radiological Society of North America Scholar Grant.* Walter R. Witschey-RELATED: Grant: National Institutes of Health.* Scott E. KasnerUNRELATED: Consultancy: Bristol Myers Squibb, Bayer, Boehringer Ingelheim, Medtronic; Expert testimony: Janssen; Grants/Grants Pending: BMS, Bayer, Medtronic, WL Gore*; Royalties: UpToDate. Laurie A. Loevner-UNRELATED: Board Membership: American Society of Neuroradiology, Foundation of the American Society of Neuroradiology, Comments: Co-Chair of the Foundation of the American Society of Neuroradiology, Board of Trustees, Board of Directors. *Money paid to the institution.

\section{REFERENCES}

1. Arenillas JF, Dieleman N, Bos D. Intracranial arterial wall imaging: techniques, clinical applicability, and future perspectives. Int J Stroke 2019;14:564-73 CrossRef Medline

2. Lindenholz A, van der Kolk AG, Zwanenburg JJM, et al. The use and pitfalls of intracranial vessel wall imaging: how we do it. Radiology 2018;286:12-28 CrossRef Medline

3. Mandell DM, Mossa-Basha M, Qiao Y, et al. Intracranial vessel wall MRI: principles and expert consensus recommendations of the American Society of Neuroradiology. AJNR Am J Neuroradiol 2017;38:218-29 CrossRef Medline

4. von Elm E, Altman DG, Egger $M$, et al. The strengthening the reporting of observational studies in epidemiology (STROBE) statement: guidelines for reporting observational studies. Lancet 2007;370:1453-57 CrossRef Medline

5. Vandenbroucke JP, von Elm E, Altman DG, et al. Strengthening the reporting of observational studies in epidemiology (STROBE): explanation and elaboration. Epidemiology 2007;18:805-35 CrossRef Medline

6. Seo HJ, Kim SY, Lee YJ, et al. A newly developed tool for classifying study designs in systematic reviews of interventions and exposures showed substantial reliability and validity. J Clin Epidemiol 2016;70:200-25 CrossRef Medline

7. Song JW, Chung KC. Observational studies: cohort and casecontrol studies. Plast Reconstr Surg 2010;126:2234-42 CrossRef Medline

8. Grimes DA, Schulz KF. An overview of clinical research: the lay of the land. Lancet 2002;359:57-61 CrossRef Medline
9. Rutjes AW, Reitsma JB, Vandenbroucke JP, et al. Case-control and two-gate designs in diagnostic accuracy studies. Clin Chem 2005;51:1335-41 CrossRef Medline

10. Kitanaka C, Tanaka J, Kuwahara M, et al. Magnetic resonance imaging study of intracranial vertebrobasilar artery dissections. Stroke 1994;25:571-75 CrossRef Medline

11. Aoki S, Shirouzu I, Sasaki Y, et al. Enhancement of the intracranial arterial wall at MR imaging: relationship to cerebral atherosclerosis. Radiology 1995;194:477-81 CrossRef Medline

12. Natori T, Sasaki M, Miyoshi M, et al. Detection of vessel wall lesions in spontaneous symptomatic vertebrobasilar artery dissection using T1-weighted 3-dimensional imaging. J Stroke Cerebrovasc Dis 2014;23:2419-24 CrossRef Medline

13. Urbach H, Meyer-Lindenberg A, Bendszus M, et al. Dissections of the basilar artery [in German]. Rofo 1998;169:170-74 CrossRef Medline

14. Ishitsuka K, Sakaki Y, Sakai S, et al. Diagnosis and follow-up of posterior inferior cerebellar artery dissection complicated with ischemic stroke assisted by T1-VISTA: a report of two cases. BMC Neurol 2016;16:121 CrossRef Medline

15. Sakurai K, Miura T, Sagisaka T, et al. Evaluation of luminal and vessel wall abnormalities in subacute and other stages of intracranial vertebrobasilar artery dissections using the volume isotropic turbo-spin-echo acquisition (VISTA) sequence: a preliminary study. J Neuroradiol 2013;40:19-28 CrossRef Medline

16. Choi JW, Han M, Hong JM, et al. Feasibility of improved motionsensitized driven-equilibrium (iMSDE) prepared 3D T1-weighted imaging in the diagnosis of vertebrobasilar artery dissection. $J$ Neuroradiol 2018;45:186-91 CrossRef Medline

17. Wang Y, Lou X, Li Y, et al. Imaging investigation of intracranial arterial dissecting aneurysms by using $3 \mathrm{~T}$ high-resolution MRI and DSA: from the interventional neuroradiologists' view. Acta Neurochir (Wien) 2014;156:515-25 CrossRef Medline

18. Kwon JY, Kim N, Suh DC, et al. Intracranial and extracranial arterial dissection presenting with ischemic stroke: lesion location and stroke mechanism. J Neurol Sci 2015;358:371-76 CrossRef Medline

19. Hirai T, Korogi Y, Murata Y, et al. Intracranial artery dissections: serial evaluation with MR imaging, MR angiography, and source images of MR angiography. Radiat Med 2003;21:86-93 Medline

20. Kim T, Choi HS, Koo J, et al. Intramural hematoma detection by susceptibility-weighted imaging in intracranial vertebral artery dissection. Cerebrovasc Dis 2013;36:292-98 CrossRef Medline

21. Mascalchi M, Bianchi MC, Mangiafico S, et al. MRI and MR angiography of vertebral artery dissection. Neuroradiology 1997;39: 329-40 CrossRef Medline

22. Takano K, Yamashita S, Takemoto K, et al. MRI of intracranial vertebral artery dissection: evaluation of intramural haematoma using a black blood, variable-flip-angle 3D turbo spin-echo sequence. Neuroradiology 2013;55:845-51 CrossRef Medline

23. Park KJ, Jung SC, Kim HS, et al. Multi-contrast high-resolution magnetic resonance findings of spontaneous and unruptured intracranial vertebral artery dissection: qualitative and quantitative analysis according to stages. Cerebrovasc Dis 2016;42:23-31 CrossRef Medline

24. Jung SC, Kim HS, Choi C, et al. Spontaneous and unruptured chronic intracranial artery dissection: high-resolution magnetic resonance imaging findings. Clin Neuroradiol 2018;28:171-81 CrossRef Medline

25. Yun SY, Heo YJ, Jeong HW, et al. Spontaneous intracranial vertebral artery dissection with acute ischemic stroke: high-resolution magnetic resonance imaging findings. Neuroradiol J 2018;31:26269 CrossRef Medline

26. Madokoro Y, Sakurai K, Kato D, et al. Utility of T1- and T2weighted high-resolution vessel wall imaging for the diagnosis and follow up of isolated posterior inferior cerebellar artery dissection with ischemic stroke: report of 4 cases and review of the 
literature. J Stroke Cerebrovasc Dis 2017;26:2645-51 CrossRef Medline

27. Mizutani T. A fatal, chronically growing basilar artery: a new type of dissecting aneurysm. J Neurosurg 1996;84:962-71 CrossRef Medline

28. Edjlali M, Gentric J, Régent-Rodriguez C, et al. Does aneurysmal wall enhancement on vessel wall MRI help to distinguish stable from unstable intracranial aneurysms? Stroke 2014;45:3704-06 CrossRef Medline

29. Park JK, Lee CS, Sim KB, et al. Imaging of the walls of saccular cerebral aneurysms with double inversion recovery black-blood sequence. J Magn Reson Imaging 2009;30:1179-83 CrossRef Medline

30. Boussel L, Wintermark M, Martin A, et al. Monitoring serial change in the lumen and outer wall of vertebrobasilar aneurysms. AJNR Am J Neuroradiol 2008;29:259-64 CrossRef Medline

31. Martin AJ, Hetts SW, Dillon WP, et al. MR imaging of partially thrombosed cerebral aneurysms: characteristics and evolution. AJNR Am J Neuroradiol 2011;32:346-51 CrossRef Medline

32. Omodaka S, Endo H, Niizuma K, et al. Quantitative assessment of circumferential enhancement along the wall of cerebral aneurysms using MR imaging. AJNR Am J Neuroradiol 2016;37:1262-66 CrossRef Medline

33. Blankena R, Kleinloog R, Verweij BH, et al. Thinner regions of intracranial aneurysm wall correlate with regions of higher wall shear stress: a 7T MRI study. AJNR Am J Neuroradiol 2016;37: 1310-17 CrossRef Medline

34. Matouk CC, Mandell DM, Günel M, et al. Vessel wall magnetic resonance imaging identifies the site of rupture in patients with multiple intracranial aneurysms: proof of principle. Neurosurgery 2013;72:492-96 CrossRef Medline

35. Kleinloog R, Korkmaz E, Zwanenburg JJM, et al. Visualization of the aneurysm wall: a 7.0-Tesla magnetic resonance imaging study. Neurosurgery 2014;75:614-22 CrossRef Medline

36. Nagahata $S$, Nagahata $M$, Obara $M$, et al. Wall enhancement of the intracranial aneurysms revealed by magnetic resonance vessel wall imaging using three-dimensional turbo spin-echo sequence with motion-sensitized driven-equilibrium: a sign of ruptured aneurysm? Clin Neuroradiol 2016;26:277-83 CrossRef Medline

37. Cheng-Ching E, Jones S, Hui FK, et al. High-resolution MRI vessel wall imaging in varicella zoster virus vasculopathy. $J$ Neurol Sci 2015;351:168-73 CrossRef Medline

38. Ide S, Kakeda S, Miyata M, et al. Intracranial vessel wall lesions in patients with systematic lupus erythematosus: vessel wall lesions in SLE patients. J Magn Reson Imaging 2018;48:1237-46 CrossRef Medline

39. Berkefeld J, Enzensberger W, Lanfermann H. MRI in human immunodeficiency virus-associated cerebral vasculitis. Neuroradiology 2000;42:526-28 CrossRef Medline

40. Thaler C, Kaufmann-Bühler A, Gansukh T, et al. Neuroradiologic characteristics of primary angiitis of the central nervous system according to the affected vessel size. Clin Neuroradiol 2019;29:3744 CrossRef Medline

41. Schuster S, Bachmann H, Thom V, et al. Subtypes of primary angiitis of the CNS identified by MRI patterns reflect the size of affected vessels. J Neurol Neurosurg Psychiatry 2017;88:749-55 CrossRef Medline

42. Küker W, Gaertner S, Nagele T, et al. Vessel wall contrast enhancement: a diagnostic sign of cerebral vasculitis. Cerebrovasc Dis 2008;26:23-29 CrossRef Medline

43. Han C, Li M, Xu Y, et al. Adult Moyamoya-atherosclerosis syndrome: clinical and vessel wall imaging features. $J$ Neurol Sci 2016;369:181-84 CrossRef Medline

44. Muraoka S, Araki Y, Taoka T, et al. Prediction of intracranial arterial stenosis progression in patients with Moyamoya vasculopathy: contrast-enhanced high-resolution magnetic resonance vessel wall imaging. World Neurosurg 2018;116:e1114-21 CrossRef Medline
45. Yu L, He H, Zhao J, et al. More precise imaging analysis and diagnosis of Moyamoya disease and Moyamoya syndrome using highresolution magnetic resonance imaging. World Neurosurg 2016; 96:252-60 CrossRef Medline

46. Wang M, Yang Y, Zhou F, et al. The contrast enhancement of intracranial arterial wall on high-resolution MRI and its clinical relevance in patients with Moyamoya vasculopathy. Sci Rep 2017;7:44264 CrossRef Medline

47. Seo W, Oh K, Suh S, et al. Clinical significance of wall changes after recanalization therapy in acute stroke: high-resolution vessel wall imaging. Stroke 2017;48:1077-80 CrossRef Medline

48. Power S, Matouk C, Casaubon LK, et al. Vessel wall magnetic resonance imaging in acute ischemic stroke: effects of embolism and mechanical thrombectomy on the arterial wall. Stroke 2014;45: 2330-34 CrossRef Medline

49. Abraham P, Scott Pannell J, Santiago-Dieppa D, et al. Vessel wall signal enhancement on 3-T MRI in acute stroke patients after stent retriever thrombectomy. Neurosurg Focus 2017;42:E20 CrossRef Medline

50. Chen $\mathrm{C}$, Chen S, Fuh J, et al. Vascular wall imaging in reversible cerebral vasoconstriction syndrome: a 3-T contrast-enhanced MRI study. J Headache Pain 2018;19:74 CrossRef Medline

51. Jiang Y, Zhu C, Peng W, et al. Ex-vivo imaging and plaque type classification of intracranial atherosclerotic plaque using high resolution MRI. Atherosclerosis 2016;249:10-16 CrossRef Medline

52. Jiang $\mathrm{W}, \mathrm{Yu} \mathrm{W}, \mathrm{Ma} \mathrm{N}$, et al. High resolution MRI guided endovascular intervention of basilar artery disease. J Neurointerv Surg 2011;3:375-78 CrossRef Medline

53. Ma N, Jiang WJ, Lou X, et al. Arterial remodeling of advanced basilar atherosclerosis: a 3-Tesla MRI study. Neurology 2010;75:25358 CrossRef Medline

54. Zhang X, Zhu C, Peng W, et al. Scan-rescan reproducibility of high-resolution magnetic resonance imaging of atherosclerotic plaque in the middle cerebral artery. PLoS One 2015;10:e134913 CrossRef Medline

55. Whelton PK, Carey RM, Aronow WS, et al. 2017 ACC/AHA/ AAPA/ABC/ACPM/AGS/APhA/ASH/ASPC/NMA/PCNA guideline for the prevention, detection, evaluation, and management of high blood pressure in adults: executive summary-a Report of the American College of Cardiology/American Heart Association Task Force on Clinical Practice Guidelines. Hypertension 2018;71: 1269-324 CrossRef Medline

56. $\mathrm{Xu} \mathrm{W}, \mathrm{Li} \mathrm{M}$, Niu J, et al. Intracranial artery atherosclerosis and lumen dilation in cerebral small-vessel diseases: a high-resolution MRI study. CNS Neurosci Ther 2014;20:364-67 CrossRef Medline

57. Kim J, Jung K, Sohn C, et al. Intracranial plaque enhancement from high resolution vessel wall magnetic resonance imaging predicts stroke recurrence. Int J Stroke 2016;11:171-79 CrossRef Medline

58. Kim YS, Lim S, Oh K, et al. The advantage of high-resolution MRI in evaluating basilar plaques: a comparison study with MRA. Atherosclerosis 2012;224:411-16 CrossRef Medline

59. Ahn S, Lee J, Kim Y, et al. Isolated MCA disease in patients without significant atherosclerotic risk factors: a high-resolution magnetic resonance imaging study. Stroke 2015;46:697-703 CrossRef Medline

60. Niu P, Yu Y, Zhou H, et al. Vessel wall differences between middle cerebral artery and basilar artery plaques on magnetic resonance imaging. Sci Rep 2016;6:38534 CrossRef Medline

61. Dieleman N, Yang W, Abrigo JM, et al. Magnetic resonance imaging of plaque morphology, burden, and distribution in patients with symptomatic middle cerebral artery stenosis. Stroke 2016; 47:1797-802 CrossRef Medline

62. Qiao Y, Anwar Z, Intrapiromkul J, et al. Patterns and implications of intracranial arterial remodeling in stroke patients. Stroke 2016;47:434-40 CrossRef Medline 
63. Langan S, Schmitt J, Coenraads PJ, et al. The reporting of observational research studies in dermatology journals: a literature-based study. Arch Dermatol 2010;146:534-41 CrossRef Medline

64. Fung AE, Palanki R, Bakri SJ, et al. Applying the CONSORT and STROBE statements to evaluate the reporting quality of neovascular age-related macular degeneration studies. Ophthalmology 2009;116:286-96 CrossRef Medline

65. Papaioannou TG, Soulis D, Tousoulis D. Reversibility of hypertension-induced subclinical vascular changes: do the new
ACC/AHA 2017 blood pressure guidelines and heart rate changes make a difference? J Clin Hypertens (Greenwich) 2019; 21:1242 CrossRef

66. Muntner P, Carey RM, Gidding S, et al. Potential US population impact of the 2017 ACC/AHA high blood pressure guideline. Circulation 2018;137:109-18 CrossRef Medline

67. Hall KL, Vogel AL, Huang GC, et al. The science of team science: a review of the empirical evidence and research gaps on collaboration in science. Am Psychol 2018;73:532-48 CrossRef Medline 